\title{
Reaching targets in the national cervical screening programme: are current practices unethical?
}

\author{
Peggy Foster and C Mary Anderson Manchester University, Manchester and General Practitioner, Stockport, \\ respectively
}

\begin{abstract}
The principle of informed consent is now well established within the National Health Service (NHS) in relation to any type of medical treatment. However, this ethical principle appears to be far less well established in relation to medical screening programmes such as Britain's national cervical screening programme. This article will critically examine the case for health care providers vigorously pursuing women to accept an invitation to be screened. It will discuss the type of information which women would need in order to make an informed decision about whether or not to be screened. The lack of such information in current patient leaflets on the "smear test" will then be documented. Finally, the article will explore possible ways of maximising women's autonomy in relation to the cervical screening programme without sacrificing any of its main benefits.
\end{abstract}

(Fournal of Medical Ethics 1998;24:151-157)

Keywords: Cervical screening; informed consent; patient autonomy

Despite receiving almost universal support from medical experts, politicians and the British public, the national cervical screening programme has attracted some criticism from those who argue that it fails to place enough emphasis on ensuring that women give their informed consent to screening and fails to empower women to act as autonomous individuals in relation to the decision whether to be screened. ${ }^{1}$ Our aim in this paper is to show how the current targets for screening a very high proportion of all adult women, combined with financial incentives to general practitioners (GPs) to reach those targets, undermine women's autonomy in relation to cervical screening. Having made this case we will go on to suggest ways in which the current screening programme might be modified in order to enhance women's autonomy without sacrificing the key benefits of screening.

\section{The case in favour of vigorously} persuading women to accept an invitation to be screened

The British national cervical screening programme's principal objective is "to prevent mortality from cervical cancer". ${ }^{2}$ The programme enjoys almost universal support from the medical profession, despite its considerable financial costs and workload burdens, primarily because it saves women's lives. For example, according to a recent unpublished survey of GPs in the North West of England, $90 \%$ of GPs agreed with the statement: "Despite the uncertainty, screening is the best way we have to prevent deaths from cervical cancer"(Anderson CM, 1994 unpublished survey). Since no clinically controlled trials of cervical screening have been carried out in Britain, or elsewhere, ${ }^{3}$ the exact relationship between high levels of screening and lower mortality rates from cervical cancer is unknown and unproven. Nevertheless, the general consensus is that Britain's falling death rate from cervical cancer in the 1990 s can be at least partly attributed to screening, and that any measure that will increase the overall uptake of screening will save extra women's lives. In 1989 1,816 women in England and Wales died from cervical cancer, by 1994 the death rate had fallen to $1,369 .{ }^{4}$ According to Ann McPherson and Joan Austoker these figures on mortality from cervical cancer clearly indicate that a well coordinated screening programme does contribute to an overall fall in the number of deaths from cervical cancer. They note that "although age-standardised mortality rates for cervical cancer in England and Wales had been falling by about 1-2\% per year from 1970 to 1988 it is only latterly that we have seen this fall increase to $7 \%$ annually in 1993 and 1994 ".

A number of medical textbooks claim that in theory at least cervical screening should be able to 
prevent virtually all cases of invasive cervical cancer. ${ }^{6}$ However, even the most fervent supporters of cervical screening acknowledge that there will always be a gap between screening practice and screening potential. Nevertheless the claims made for Britain's national cervical screening programme are impressive. For example, according to Baroness Cumberledge, Minister for Health in 1993, the national screening programme should eventually reduce deaths from cervical cancer by about 80 per cent. ${ }^{7}$ Some strong supporters of the current screening programme have even claimed that without it the numbers of women dying from cervical cancer would have risen significantly, due primarily to an increase in risky sexual behaviour by young women. For example, in October 1994 Dr Muir Gray, Secretary of the National Coordinating Network claimed that up to 2,000 women's lives were being saved by the screening programme each year. He based this surprisingly high figure on his belief that "If there had been no screening programme ... mortality would have gone up". ${ }^{8}$ This claim, however, is simply a guesstimate, based on some evidence of a rise in cervical cancer in young women, and other experts would dispute the claim that without screening deaths from cervical cancer would have risen dramatically in recent years. ${ }^{13}$

As well as the generally accepted, but scientifically unproven, causal link between wellorganised screening programmes and a fall in deaths from cervical cancer, supporters of the cervical smear test also defend it on the grounds that without it a significant number of women each year would go through the trauma of a diagnosis of invasive cervical cancer followed by radical surgery or radiotherapy. ${ }^{9}$ Again the exact number of women who are protected against invasive cancer through the screening programme is unknown since experts cannot accurately predict which abnormal smears would definitely go on to become invasive cancer if left untreated. ${ }^{10}$ What is becoming clear is that the number of women, particularly young women, diagnosed through screening as having abnormal cells that are deemed to need treatment is far higher than the number who might possibly go on to develop a life-threatening cancer of the cervix. In 1989 17,818 women in England and Wales were found through screening to have carcinoma in situ or cervical intraepithelial neoplasia. ${ }^{11}$ Given the much lower number of women who were dying from invasive cervical cancer in the years before screening was common, it is inconceivable that all these 17,818 cases would have progressed to invasive cancer if left untreated. A similar comparison has recently been made by those responsible for the Bristol screening programme. They compared the large number of women found to have cerviçal abnormalities with the much small number if cases of invasive cervical cancer registered in Bris tol in previous years. They concluded that "during each screening round in Bristol, over 15,0 healthy women are incorrectly told that they afe 'at risk' (of developing cervical cancer), over 5,500 women are being investigated, with many als5o treated for a disease that would never hate troubled them". ${ }^{12}$ Presumably, supporters of the current screening programme, who have not suc gested modifying the programme in the light of these findings, are convinced that the prevention of cervical cancer in a relatively small number of women fully justifies the possible over-treatment of a much larger number of women who haye abnormal smear test results.

What women need in order to give their informed consent to screening According to Petr Skrabanek, patient autonomy@ one of the four pillars on which medical ethics ds founded, the other three being non-maleficence, beneficence and justice. ${ }^{13}$ The concept of at tonomy in relation to medical decision-making क्षs clearly complex and in many ways problematig. Patients making medical decisions will be influ enced not only by the amount of medical information they receive and understand but also by their cultural, social and religious backgrounds. Women taking decisions about their ow health and health care may, for example, sometimes be strongly influenced by their mase partners. We do not therefore claim that wome who are given full and accurate medical infosmation about cervical screening will become fully autonomous decision-makers in this area of their lives. Nevertheless, we support the goal $8 \mathrm{ff}$ enhancing patient autonomy in whatever wats possible, and one generally agreed element of patient autonomy is informed consent to mediogl interventions.

Patients cannot make relatively autonomous decisions about their medical care if they are net assisted by medical experts to gain enough knowedge and understanding to make a rational choiç According to Beauchamp and Childress, for example, "respect for autonomy obligates professionals to disclose information, to probe for and ensure understanding and voluntariness, and $\&$ foster adequate decision making". ${ }^{14}$ In a furthबr clarification of the issues of patient autonomy ard informed consent Raanan Gillon states: "Fgr medical interventions it is widely accepted the consent means a voluntary, uncoerced decision, 
made by a sufficiently competent or autonomous person on the basis of adequate information and deliberation, to accept rather than reject some proposed course of action that will affect him or her. Consent in this sense requires action by an autonomous agent based on adequate information and is by definition informed consent". ${ }^{15}$ It is difficult to see how women can make an informed choice about whether or not to join the screening programme without being given some indication of the potential risks as well as the potential benefits to them of having the test. We would argue that if the principle of informed consent is to be put into practice within the national cervical screening programme, women need accurate, understandable information on the following aspects of cervical screening. First, women need at least some rough and ready information about their particular risk of developing cervical cancer. They need to know whether their risk is virtually non-existent or whether it is relatively high. Given that no one is claiming that undergoing a screening test is a desirable or enjoyable activity in its own right, it would hardly seem rational for an individual with a near zero risk of developing cervical cancer to undergo regular screening. Second, women need to know what it will be like to undergo the initial smear test. Might the test be uncomfortable or even painful? Will it involve a vaginal examination which they might find embarrassing or even distressing ? Third, women need to have some understanding about the potential accuracy of the smear test. Does it always prevent cancer from developing ? How often does the test wrongly tell women that they are likely to develop cervical cancer unless they undergo treatment? Finally, women need to know some brief details about what will happen to them if their smear test is "positive". They need to know, for example, that investigation of and treatment for cervical abnormalities often involves some physical and emotional pain. Without this knowledge many women may accept an invitation for a smear which then locks them into a potentially distressing process of which they were quite unaware when making their initial decision whether to be screened.

\section{The lack of accurate information in patient leaflets}

Current medical practice in relation to cervical screening emphasises the need for health care providers to persuade all women to accept invitations to be screened and appears to place no weight on the need to give women accurate information on the risks and disadvantages to them of being screened. We suggest that one very important reason for this emphasis is the existence of targets to be achieved by all those involved in cervical screening in Britain.

Both health care managers and individual general practices are now being judged against nationally set criteria for maximising women's uptake of cervical screening. The current national targets for England and Wales are described thus : "Over $95 \%$ of women aged 25 to 64 should have been identified and invited for an initial smear ... . Less than $10 \%$ of women aged 25 to 64 in the population should be presumed to be "non responders" and "Over $80 \%$ of eligible women aged 25 to 64 should have had an adequate smear within the preceding 5 years. ${ }^{" 16}$ In order to ensure that all general practices do their utmost to help achieve these national targets general practitioners who manage to take smears from $80 \%$ of their target age group of female patients receive a substantial payment. A much lower sum is given to those GPs who reach only $50 \%$ of their target population. ${ }^{17}$ Several GPs surveyed in 1994 agreed that their screening behaviour was influenced by these financial targets. One GP commented: "We are afraid of missing our targets, not missing a cancer", whilst another admitted: "I'm keen to do smears but to be honest more for the targets than for the benefit to patients"(Anderson CM, unpublished). There is also some limited published evidence of the effects of target payments on GPs' screening activities. In 1990 a follow up survey of a group of GPs who had previously had low or high involvement with screening found that two thirds of GPs in the low interest group had increased their cervical screening activity primarily because of the increased financial incentives to do so. ${ }^{18}$

There is a great deal of published material and advice designed to help local health authorities and GPs to reach their screening targets. Local health authorities distribute patient information leaflets to GPs which are designed to accompany invitations to be screened. We examined ten leaflets distributed by health authorities in the North West of England in the mid-1990s and found that a number of them contained material that sounded more like propaganda for the test than accurate information on women's need for it. One leaflet, for example, urged women to "encourage your friends and relatives to have a smear ... REMEMBER - regular smears save lives ... Pass the message on". Another leaflet claimed in bold type "You are never too young or too old to start having smear tests", whilst another answered the question "Who Needs This Test ?" with "You do! - If you are between 20 and 64". Yet the risk of 
developing cervical cancer is known to be associated with age, social class, sexual activity and smoking. ${ }^{17}$ Mortality statistics show clearly that the risk of dying of cervical cancer is closely related to age and social class. In 1988-89 in England and Wales there were only 10 registered deaths from cervical cancer in women aged 20-24 and only 23 deaths in women aged 25-29 compared to 84 deaths in women aged 30-34, 142 deaths in women aged 40-44 and 194 deaths in women aged $60-64 .^{19}$ In 1981 the standardised mortality ratio for cervical cancer was 29 for social class 1 compared to 186 for social class $\mathrm{V}^{20}$ While it is a myth that nuns never develop cervical cancer, ${ }^{21}$ all experts would agree that a 20 -yearold virgin has an infinitesimal chance of dying from cervical cancer. At the other end of the risk spectrum a 40-year-old woman who has smoked for years, who has had a high number of sexual partners, or a partner in a manual occupation who has had a number of sexual partners, has a relatively high risk of developing cervical cancer within the next few years of her life.

\section{Inherent innacuracy}

As well as failing to inform women about the varying risk of developing cervical cancer, most of the leaflets we examined played down the fact that a significant minority of women experience the smear test as painful and/or embarrassing. ${ }^{22}$ Two out of the ten leaflets we surveyed stated that there was "no pain" involved in the test. One leaflet stated that some women do experience "some discomfort" whilst another claimed that the test was "at the most slightly uncomfortable". Only one leaflet acknowledged that some women find the test "very uncomfortable", and only one leaflet told women that the test was "sometimes embarrassing". Two leaflets did not even make it clear that the test involves a vaginal examination. Yet for some women, for example women who have been raped or sexually abused, any type of vaginal examination can be particularly distressing. One woman has commented: "I am a rape victim and I don't think doctors have even thought about how traumatic intimate examinations can be for a woman like me". ${ }^{23}$

The third type of information we looked for in the leaflets we examined was some indication about the inherent inaccuracy of the current cervical screening test. In 1994 the National Co-ordinating Network did advise that the smear test's inherent unreliability should be made clear to the public and the press so that cases of interobserver variability would not be wrongly treated as negligent or incompetent. ${ }^{24}$ The report emphasised that "All screening programmes must have false positives and false negatives. It is impossib to run a screening programme without false pos? tives and false negatives. This information should be made clearly available to women being offeref screening". ${ }^{24}$ A more recent NHS Cervica Screening Programme publication entitled In proving the Quality of the Written Information Sent $\$$ Women about Cervical Screening has recommended that both invitation letters and leaflets shoufel contain information to indicate that a normal test result "means low risk not no risk of developing cervical cancer". ${ }^{25}$

None of the ten leaflets we examined made an attempt to explain to women the inheregf problem of false positives and false negatives. If 1996 the Health Education Authority issued revised patient information leaflet which did stat? "As with other medical tests cervical screening $\$$ not 100 per cent perfect". ${ }^{26}$ However, this simple sentence hardly begins to convey the message the the smear test is intrinsically inaccurate. Y according to two experts on cervical screening $\overrightarrow{0}$ writing for a medical audience - the current test $\frac{\xi}{8}$ unable "to confidently predict which cases (if abnormal cells) will progress (to become invasige cancer) and which will regress. The identification of more certain prognostic factors is a necessany prerequisite to improving the efficiency of the screening programme. In their absence it is inev table that many women with lesions which ma have spontaneously regressed will continue to be unnecessarily treated". ${ }^{10}$

This complex issue of false positive test resulys is taken seriously by screening experts becaus they are now fully aware that a false positive test result can impose significant psychological and physical harm on a woman who receives it. Posner and Vessey's research into patients' experiences of cervical screening, for example, found very high levels of anxiety in women who had received positive smear test result. Several women in the study reported that they immediately assumed that they might well have a life-threatening cancero One woman commented: "I thought it was termi nal. Anything associated with cancer, you always think the worst", whilst another reported "I lost half a stone in weight. I lost my appetite, felt sicf I had this awful feeling it was going to bse cancer". ${ }^{27}$

Women who receive treatment following a pos tive smear test result have been found to continư to suffer high levels of anxiety as well as frequen suffering physical pain and discomfort bo during and after treatment. Posner and Vessey found that over $40 \%$ of women having outpatient treatment by laser or cryocautery experience्f pain or other symptoms which they described $\overline{a s}$ 
severe, while $30 \%$ experienced post treatment pain. ${ }^{28}$ After treatment for cervical abnormalities a significant number of women also suffer "adverse psychosexual sequelae" such as an increase in negative attitudes towards sexual intercourse or towards a regular sexual partner" ${ }^{29}$

\section{Other tactics used to maximise screening uptake}

As well as producing information leaflets which appear to be designed to persuade as many women as possible to accept invitations to be screened, there are a number of other ways in which screening providers can exert strong influence over their female patients. In recent years general practitioners have been advised by articles in both prestigious medical journals such as the British Medical fournal and magazines distributed free of charge to doctors, such as $G P$ and Pulse, on how to increase the uptake of cervical screening amongst their patients. In 1989 an article in Update entitled "How to Achieve Cervical Cytology Targets" advised GPs that "in women of more than 60 years old the procedure for taking smears can be both painful and yield insufficient material. However, if targets are to be achieved we are going to have to persuade some pensioners of the value of cervical cytology screening". ${ }^{30}$ At least this article did continue: "One must preserve a degree of humanity here and if these patients do not wish to have a smear their opinion should be respected". ${ }^{30}$ In 1994, Dr Gallen, a family doctor in Wellingborough, advised GPs in an article entitled "Hit that target" that it is essential to "List and chase (our emphasis) defaulters who have not responded within three months of the first invitation to a smear test". ${ }^{31}$ An article published in the British Medical fournal in 1990 advised GPs that if a new female patient is due for a smear "offer to perform one straight away... . Similarly a woman attending for reasons unconnected with cervical cytology should have the date of her last smear checked and if appropriate be offered a smear on the spot or a future appointment... . Opportunistic smears can also be offered during health promotion clinics for women ... or a hormone replacement therapy clinic". ${ }^{32}$ None of the "advice" articles which we read questioned the ethics of taking "opportunistic" smears nor did they address the issue of whether patients have enough time or information to give their informed consent to a smear test offered to them during a consultation for a quite separate purpose.
What is ethically unacceptable about these persuasive tactics?

Supporters of the current national cervical screening programme might well argue that persuasive tactics such as those outlined above may occasionally lead to some very reluctant women coming under considerable pressure to accept a smear test, but that this pressure is justified if even a very small number of women are saved from unnecessary life-threatening and traumatic invasive cancer. In other words, it is ethically permissible for medical experts, and they may even have a medical duty, to override the ill-informed or irrational decisions of their patients if by doing so they save lives and prevent significant harm occurring in at least some of those whose autonomous decisions they override. We do not accept that this form of medical paternalism is ethically permissible in relation to cervical screening on two grounds. First, we would argue that the supporters of cervical screening do not have a particularly convincing case in claiming that the benefits to women of being screened, even in cases where women find the process very distressing, clearly outweigh the harm imposed on them. As we have already pointed out, the intrinsic unreliability of the particular screening test currently on offer suggests that the balance of costs and benefits to individual women screened is far less clear cut than many supporters of screening assume, in which case the argument that screening providers who use persuasive tactics are simply giving priority to the ethical principle of medical beneficence over the principle of informed consent looks less strong.

Second, even if supporters of cervical screening reject the claim that there are more risks and less benefits associated with screening than have generally been recognised and insist that women who decline all invitations to undergo cervical screening are taking an "unacceptable" risk with their long term health, we would argue that as autonomous adults, women have a right to take such a risk in this area of their lives. We would therefore claim that it is not ethical for screening providers to attempt to override a woman's decision not to be screened by using methods that go beyond simply giving women the benefit of their own opinion that screening is worthwhile. Just because lives may be saved through cervical screening does not in itself justify manipulative forms of medical persuasion. We allow women to take all sorts of non-medical risks with their health and wellbeing, such as the risk of driving a fast car or undertaking a dangerous sport such as mountaineering. There appears to be no logical reason therefore why supporters of screening should not accept a 
woman's decision to take the risk of not being screened, particularly if she has received information telling her of the potential benefits of the screening programme.

The current craze for all types of health promotion and preventive medicine should not be allowed to obscure the weight of evidence that shows that this type of public expenditure appears to bring only marginal benefits in terms of lives saved or prolonged compared to socio-economic policies that directly improve the health and wellbeing of the poorest sections of society. ${ }^{33}$ Even if the majority of women screened for cervical and breast cancer suffer only minor inconvenience as the only negative side effect of the screening process, over-zealous attempts to persuade women to be screened still contribute to the ever-increasing medicalisation of women's lives with a concomitant risk of increased medical control and surveillance over women's lives.

\section{Can we maximise women's autonomy without sacrificing the main benefits of cervical screening?}

We have argued that the cervical screening programme as currently run is in danger of overriding healthy women's autonomy in two ways. First, women are being manipulated by invitation leaflets, which emphasise only the benefits of screening, into regarding the smear test as wholly beneficial. Without seeing any of the evidence on the risks and disadvantages of the current test women are not able to give their fully informed consent to screening. Second, some practices, such as taking opportunistic smears during a consultation for another purpose, are more manipulative than persuasive leaflets and verge on unacceptable arm-twisting of women. Is there perhaps a way of tackling these two barriers to informed consent to screening without sacrificing the whole aims and objectives of the programme? We think there are two reforms to the screening programme which could well be implemented without any significant reduction in screening uptake occurring.

First, patient information leaflets could be redesigned to include at least some information on the potential risks and disadvantages of the cervical smear test. Women could be informed that some women find the test painful and/or embarrassing. They could also be told that the test is intrinsically inaccurate and cannot therefore detect all cases of pre-cancerous cervical abnormalities, whilst detecting some abnormalities that would never develop into invasive cancer during a woman's lifetime. Finally the leaflets could give women at least some very basic information of their particular risk of developing cervical cancoi in terms of their age, sexual status and possib social class. Such information might lead to a very small increase in the number of women declining an invitation to be screened but this would be highly unlikely to lead to any significant increas in the incidence of cervical cancer.

Second, the system of financially rewardinfg GPs for reaching high screening targets could be modified. We should emphasise at this point tha् we have no ethical objections to GPs being rewarded financially for carrying out cervic screening per se, we are simply objecting to the unintended consequence of these financial tat gets, which is that just one or two women whif decline to be screened can, in effect, cost a GP up to two thousand pounds of annual income. Under such circumstances it is hardly surprising if $\vec{a}$ small minority if GPs put these "refusers" क्षे "defaulters" under considerable pressure to a cept a smear test. We would therefore suggest thg the screening targets be modified to allow GPs include in their target numbers any women why have signed a form to indicate that they do ner wish to be included in the screening programmo. Again we do not envisage that such a chang would lead to large numbers of women opting out of the programme but it would prevent wome who are quite clear that they do not wish undergo the test from coming under undue pres sure from their GP to accept it.

Given the general medical consensus that the current cervical screening programme saves live् and given the very strong backing for this programme from politicians, the media and popular women's magazines it is highly unlike that the two modifications we have suggestegl above would alter the majority of woments decisions on whether or not to be screened. If small number of women dropped out of the programme because of these reforms we would regard this as an indication that womens autonomy was being given greater weight withyu the programme. This would in turn make the screening programme more ethically acceptable those who regard the goal of patient autonomy 8 an essential element of all forms of medical intex vention, particularly those that target healti. individuals in order perhaps to prevent a possib future medical problem. Finally we shouß emphasise again that we do not believe that ary very small drop in take up of cervical screening which resulted from the changes we hame proposed would in any way seriously endanger th⿸户ㅏㅇ programme's two ultimate objectives of reducing 
both the incidence of, and mortality from, invasive cervical cancer.

\section{Acknowledgements}

The authors would like to thank Eve Garrard for her very generous advice and constructive comments on an earlier version of this paper.

Peggy Foster, PhD, is Senior Lecturer in Social Policy, School of Social Policy, University of Manchester, Manchester. C Mary Anderson is a General Practitioner in Heaton Moor Medical Centre, Stockport.

\section{References}

1 See, for example, Skrabanek P. Why is preventive medicine exempted from ethical constraints? Fournal of Medical Ethics 1990;16:187-90.

2 National Co-ordinating Network. Assuring the quality and measuring the effectiveness of cervical screening. Oxford: NHSCSP, 1994:13.

3 McCormick J. Cervical smears: a questionable practice? Lancet 1989; ii 207-9.

4 McPherson A, Austoker J. Cervical cytology. In: McPherson A, Waller D, eds. Women's health [4th ed]. Oxford: Oxford University Press, 1997:382.

5 See reference $4: 382$

6 See, for example, Clarke-Pearson DL, Dowood MY. Green's gynecology: essentials of clinical practice [4th ed]. Boston: Little, Brown \& Company, 1990:509.

7 MacPherson S, Haines P. Is this the best way to save life? GP 1993 Oct 29: 29.

8 Laurance J. Smear tests save 2,000 lives a year. The Times 1994 Oct 12:6.

9 See for example, Smith A, Jacobson B. The nation's health: a strategy for the 1990s. London: King's Hospital Fund for London, 1988:98.

10 Wilson S, Woodman CBJ. Costs and benefits of cervical screening. In: Luesley D, Jordan J, Richart RM, eds. Intraepithelial neoplasia of the lower genital tract. Edinburgh: Churchill Livingstone, 1994:64.

11 See reference 4: 381 .

12 Raffle AE, Alden B, Mackenzie EFD. Detection rates for abnormal cervical smears: what are we screening for? Lancet 1995; 345:1469-73.
13 Skrabanek P. The ethics of prevention. In: Le Fanu J, ed. Preventionitis: the exaggerated claims of health promotion. London: The Social Affairs Unit, 1994:118.

14 Beauchamp T, Childress J. Principles of biomedical ethics [4th ed]. Oxford: Oxford University Press, 1994:127.

15 Gillon R. Philosophical medical ethics. Chichester: John Wiley \& Sons, 1985:113.

16 See reference 2: 17.

17 McPherson A, Austoker J. Cervical cytology. In: McPherson A, Waller D, eds. Women's health [4th ed]. Oxford: Oxford University Press, 1997.

18 Corney $\mathrm{R}$. Changes in preventive medicine among general practitioners. Health Trends 1994; 24:139-42.

19 Cancer Research Campaign. Cancer of the cervix uteri. Cancer Research Campaign fact sheet 12:2. Oxford: Cancer Research Campaign, 1990.

20 Variations Sub-Group of the Chief medical Officer's Health of the Nation Working Group. Variations in health: what can the Department of Health and the NHS do? London: Department of Health, 1995:141.

21 Skrabanek P. Cervical cancer in nuns and prostitutes: a plea for scientific continence. Fournal of Clinical Epidemiology 1988; 41:577-82.

22 Shwartz M, Savage W, George J, Emohare L. Women's knowledge and experience of cervical screening: a failure of health education and medical organisation. Community Medicine 1989; 11:279-89.

23 Neustatter A. The screening crisis. New Woman 1992 Apr:43.

24 See reference 2: 5.

25 Austoker J, Davey C, Jansen C. Improving the quality of the written information sent to women about cervical screening. Sheffield: NHSCSP, 1997:9.

26 Health Education Authority. NHS cervical screening: your smear test. London: Health Education Authority, 1996.

27 Posner T, Vessey M. Prevention of cervical cancer - the patient's view. London: King Edward's Hospital Fund for London, 1988: 45.

28 See reference 27: 34 .

29 Campion MJ, et al. Psychosexual trauma of an abnormal cervical smear. British fournal of Obstetrics and Gynaecology 1988; 95:175-81.

30 Mead MG. How to achieve cervical cytology targets. Update 1989 Dec 1:1040-6.

31 Gallen D. Hit that target. Doctor 1994 Oct 12:72.

32 Chomet J, Chomet J. Cervical screening in general practice: a "new" scenario. British Medical fournal 1990; 300:1505.

33 Foster P. Inequalities in health: what health systems can and cannot do. Fournal of Health Services Research and Policy 1996;1: 179-82.

\section{News and notes}

\section{IVth World Congress of IAB}

The IVth World Congress of the International Association of Bioethics, Global Bioethics: East and West, South and North, will be held from 4 - 6 November this year in Ichigaya,Tokyo, Japan. Up to date information and call for abstracts will be available on the Internet through: http://www.uclan.ac.facs/ethics/iab.htm and http://www.biol.tsukuba.ac.jp/ macer/IAB4.html
Also, for information, contact: Professor Hyakudai Sakamoto, President, The East Asian Association for Bioethics, c/o University Research Center, Nihon University, 4-8-24 Kudan-Minami, Chiyoda-ku,Tokyo 102, Japan. Fax: int +81352758 326; e-mail: sakamoto@chs.nihon-u.ac.jp 